\title{
Application of the Interior Decoration Materials in Environmental Engineering
}

\author{
Sijia Zhang ${ }^{1}$, Weida Shi $^{2}$ \\ ${ }^{1}$ Environmental Art Design, Hebei Institute of Fine Arts,XinLe,ShiJiaZhuang,050700,China. \\ ${ }^{1}$ Environmental Art Design, Hebei Institute of Fine Arts,XinLe,ShiJiaZhuang,050700,China.
}

Xiaodong123@163.com

Keywords: Domestic Design, Traditional materials, Interior decoration materials.

\begin{abstract}
At present, the research and application on material still stays in the primary stage in domestic, mainly by introducing the foreign advanced technology and experience, rare in independent research and new materials development of technology. Proceeding from our national conditions, we should focus on the materials which is resource conservation and economic. In recent years, when continuously develop the new materials, they do not forget to grasp of environmental protection at the same time abroad, a large number of energy conservation and environmental protection green harmless material has been created. Because of the boomy of China's real estate, decoration has become the most popular topic in people's life, according to the statistics, decoration output value exceed more than 300 billion yuan a year. Due to heavy pollution and poor effect, the previous materials already can't satisfy people's needs. New material has good performance and decorative effect, what is important is the character of green environmental protection, and it become the new hot consumption.
\end{abstract}

\section{Section One: The characteristics and development of new materials}

New decorative material is safe and environmental protection, has the advantages of superior performance, easy operation, low cost, predominant than other material. Supported by a great number of developers and consumers.

Materials for exterior wall decoration. Decoration for Exterior wall is an important content of building decoration, materials for outer wall decoration generally have strong practicability. His purpose is to improve the ability to resist the attacking damage various nature factors such as dust, rain and snow, and freezing, and satisfy the function required such as heat insulation, sound insulation, waterproof, beautify, etc, with wall structure together. Common exterior wall decoration materials include: exterior wall coating: coating is refers to the material which can float on the surface and form tough protective film. Architectural coatings is an economic, simple construction, short time, high efficiency building decoration material, which adornment effect is good, easy maintenance. Ceramic decoration materials: ceramic wall is durable, colorful and has rich decorative effect, and easy to clean, fireproof, water resistance and abrasion resistance. The most important advantages is of corrosion resistance and low maintenance cost. The stone including natural veneer stone and artificial stone (marble, granite), the effect of natural veneer stone for adornment is good, durable, but the cost is expensive. Artificial stone has a light weight, high strength, corrosion resistance, low price, convenient construction.

Interior decoration materials. Interior wall decoration is a part of interior decoration. It can take both requirement of using and protecting structure into account. There have the Commonly used interior wall decoration materials: interior wall coating: various, colorful, fantastic effect . Facing stone: natural facing stone marble, is used for interior wall decoration mostly. And artificial veneer (artificial marble, prefabricated water tablets) is widely used in interior decoration too. Glazed tile: common glazed tile are white, color, printing color, color Mosaic and color murals, glazed tile has the character of surface smooth, beautiful, easy to clean, water resistance, waterproof. Interior wall decoration panel: there has plastic panel, fiber board, metal panels, plywood veneer, etc. 


\section{Section Two: The ground adornment material}

Ground adornment material should be security (refer to the stability and safety such as flame retardant, slip resistance, electric insulation, etc.), durable, comfortable (refers to the elastic when walking, sound insulation and sound-absorbing, etc.), decorative. The commonly used Decorative material has the following several kinds

(1) The wood floor: it is a kind of traditional ground material. Wood floor is simple and concise, comfortable, elastic walking, beautiful, expensive. Which is a kind of more advanced ground decorates material.

(2) Stone: stone floor mainly refers to natural marble and granite. They are elegant and luxuriant, adornment effect is good, but the price is expensive, it is a kind of advanced ground decorates material.

(3) Ceramic tile: ceramic floor tile durable, colorful, easy to clean, fire prevention, corrosion resistance, so the application is very extensive.

(4) Plastic floor: compared with paint, carpet, plastic floor usability is better, adaptation is strong, corrosion resistance, comfortable walking, adornment effect is good, and the price is moderate.

If we want to achieve the target of updating architectural for via the change of material, we need to have a clear understanding of the material itself. It's like we must be familiar with the vocabulary before writing. We know more about traditional materials because of the mature processing and construction craft, but for new building materials, people know less relatively. The limitations awareness about new material greatly hinder the implementation of the designers.

From the actual status of $t$ architectural design in domestic, due to awareness lacking of material, there often appear follow trend phenomenon, brick, glass curtain, sheet metal, had been used in same trend form on the building materials. Caused the public's visual fatigue and disgust eventually. For this reason, we should also do more investigation, familiar with the development of new materials and features.

There have profound theoretical system for each research and development for new material. Of course we don't need to get fully understand about its principle and production process, but what we should get comprehend is the character about the material, construct, suitable for which object and serviceable range, etc. In addition to learning the new material, we can still continue to exploit their features and performance of the traditional material, by varying structure to achieve innovation.

\section{Section Three: The exterior wall coating}

Coating is the liquid material generally refers to the composition of adhesive, coating liquid of additives and pigment directly connected with the object surface. Application of coating is very extensive, often used for building external walls, floor, ceiling, roof waterproofing, etc. The biggest characteristic of exterior wall coating is that it can well reflect the variation of the building blocks, can create the seamless effect in widespread. At the same time it can provide us with the abundant optional colors, the cost and construction technical requirements are relatively low. Because itself doesn't provide too much visual details, when take that in design, we should be deliberate about the block combination, color contrast.

In the design, you can use a single color of paint and also use a variety of color combinations, single white coating can reduce the visual component of the outer wall material, purify the visual, can produce the feeling of pure and elegant aesthetic. White as the background, it can set out the details of the surroundings really. A large area of black can present a deep, mysterious visual effect, Because the contrast for light and dark is weak, usually it can hide some deficient details. Black used in large should pay attention to avoid the atmosphere of dreary and depressing. We can through the transparent glass material , local bright way to transfigure. A large area of grey paint can create soft artistic visual effect between white and black. Different color coating can create 
abundant visual effect. Many design success by the combination of the building blocks, coating colorific.

Water concrete. The boomy of water Concrete is the period of the modernism architecture flourished, purely functional, economic, construction technology, ascribe to the same concrete building form., lacking of details. The result would be different if take design into concrete. Natural and optional.

Since the 1970 s. Famous Japanese architect Tadao ando was well known for his distinctive lighting design, delicate and elegant detail, strong sense of collection, the profound eastern philosophy. Among his works, concrete has become its landmark building materials, his works often shows exquisite texture of mechanical processing, letting more designer rediscovering the endless charm of the concrete. Then there rise the "concrete" hot.At the same time, the abuse of industrialization stylized unification of glass curtain wall, stone, brick in building decoration also makes people have a rebellious attitude. Natural, simple design style has become goals that people pursuit of. So that concrete has some new markets.

Different design pursuit different use of concrete, some people pursuit exquisite, strive to express the feeling of elegance. Some pursuit the rough strength feeling, keeping the traces of construction, pay attention to the authenticity of the performance. Another is the combination for rough and exquisite, making the structure looks elegant from overall, but powerful and rugged from close.

Ceramic bricks. For the pursuit of traditional beautiful craft, and in addition, in order to meet the requirement about light and thin which represent modern decoration materials ,then the new material appeared.

In our country, brick used for exterior wall often paste by artificial workers. The advantage is construct convenient, especially for the lower and rich region for human cost. The disadvantage is that they can't guarantee the brick paste craft, what's more, long time soaking by rain and ruin by winter freeze-thaw hide safety trouble. In Japan, the most common method is to place and pouring the brick on concrete structure beforehand, therefore, tile and brick joint is closely and not easy to fall off the back.. This construction craft demanding high technology .As in the recent years advocates the spirit of environmental protection and energy saving in domestic, there appear the way factory paste the external tile on insulation board. Then put the finished plate fixed on the wall. Most of the brick has good durability, self-cleaning, corrosion resistance, etc, at the same time the price is relatively cheap, so it is easy to find in domestic use ceramic bricks both inside and outside wall.

Anticorrosive wood materials. The advantage of lumber can give a person sense of natural warm, both feel better in look and feel. But its shortcoming is weather resistance, durability. Hard to maintenance. Therefore, we rarely find it's decorate as external material directly. However, the research and development of new materials handled this problem. Adopting preservative treatment of wood (vacuum pressure, atmospheric soaking, spraying method), prolong the service life of its use in the outdoor environment, combined with the reasonable use and maintenance, ,some outdoor wood now can reach more than 20 years or 30 to 40 years of life.

Stone walls. Laying stones, the using of stone material just like laying brick masonry together, mainly through their weighing, generally applied in design for thicker wall which is not very high. We common lay pebble, not only aesthetically pleasing, and natural. At the same time also reflect a certain local cultural characteristics.

\section{Summary}

The common exterior wall material basically has the following kinds:

Exterior wall coating: it's common in life, cheaper prices than complex material, construction method is relatively simple. But the climate resistance, self-cleaning property is relatively poor. Water concrete: give the naturally feel on the visual sense, demand higher constructing technology, secondary construction needs to be done. For example, in order to improve the exterior clean, weather resistance and durability. Water brick, better visual effect, appearance more naturally, good in durability. However, maintenance cycle is long. Ceramic tile: the price is quite cheap, simple 
construction, durability, ideal self-cleaning . But the quality is hard to control, monitor, easy to fall off cuts. Stone wall facade: the price is high, the effect is good, self-cleaning, durable, weather resistance. Metal panel: price is high, effect is good, self-cleaning, durable. Wood (preservative) : the price is higher, the effect is natural and pure, durable weather resistance and self-cleaning are general. Glass curtain: high price, durable weather resistance and self-cleaning is pretty good.

Vitreous brick: the price is higher, can create a special visual effect, hot weather resistance and self-cleaning property is better. The problem of poor thermal remains the same. U-shaped glass: the price is higher than glass curtain, special visual effect, durability, weather resistance, self-cleaning .But the thermal property is bad. Part of the roof material need to provide a good waterproof performance, so the request about durability, weather resistance is higher. In addition, designers should pay attention to the visual effect of the ground material about sensory effects. Concrete, cement material: the price is low, but easy to create dust, and is often used for low-grade building or a combination of floor coating. Terrazzo: look and feel good, can make it a variety of color and texture, excellent wear resistance. Floor coating: the price is cheaper, the color is abundant, and can be combined with transparent color coating concrete ground, used in primary processing such as terrazzo floor. Using Select for appropriate material push the development of architectural design to a new height. In general, designers should create works before study deep about each properties of material.

\section{References}

[1] Interior Decoration Materials, Cai Shaoxiang , Chemical Industry Press, 2010-9-1

[2] 21st Ccentury Institutions of Hhigher Learning, Interior Decoration Materials and Cconstruction, Chen Xuejie, China Electric Power Press, 2009-4-1

[3] Interior Decoration Materials and Construct tutorial, The National Higher Vocational Education of Art Design Professional, Zhangqian, Investigation Southwest Normal University Press, 2007-5-1

[4] Interior Decoration Materials in Colleges and Universities, Zhang Qqiumei, Xiang Shilong, Zhang Qiuhui, China Forestry Publishing House ,2003-4-1

[5] Interior Decoration Materials, Guo Hongwu, Water Conservancy and Hydropower Press, 2013-7-1

[6] The Construction of Interior Decoration Materials , Chen Xuejie, Industry Summit People's Posts and Telecommunications Publishing House 2013-6-1 